\title{
SMALL ROV MARINE BOAT FOR BATHYMETRY SURVEYS OF SHALLOW WATERS - POTENTIAL IMPLEMENTATION IN MALAYSIA
}

\author{
Ketut Tomy Suhari ${ }^{\mathrm{a}}$, Hairi Karim ${ }^{\mathrm{b}}$, Putu Harry Gunawan ${ }^{\mathrm{c}}$, and Hery Purwanto ${ }^{\mathrm{d}}$ \\ ${ }^{\text {a }}$ School of Geodesy and Geoinformation Engineering, Singaraja, Bali, Indonesia - ketut.tomy.suhari@ gmail.com \\ ${ }^{\mathrm{b}}$ I Net Spatial Sdn. Bhd, 81300, Skudai, Johor, Malaysia - wmhairi@inetspatial.com \\ ${ }^{\mathrm{c}}$ Geodesy Engineering, Faculty of Civil and Planning, National Institute of Technology Malang - \\ bandol_haryono@yahoo.com \\ ${ }^{\mathrm{d}}$ School of Computing, Telkom University - harry.gunawan.putu@ gmail.com Indonesia.
}

KEY WORDS: Hydrographics, ROV boat, shallow water, real time measurement, riverbed modelling.

\begin{abstract}
Current practices in bathymetry survey (available method) are indeed having some limitations. New technologies for bathymetry survey such as using unmanned boat has becoming popular in developed countries - filled in and served those limitations of existing survey methods. Malaysia as one of tropical country has it own river/water body characteristics and suitable approaches in conducting bathymetry survey. Thus, a study on this emerging technology should be conducted using enhanced version of small ROV boat with Malaysian rivers and best approaches so that the surveyors get benefits from the innovative surveying product. Among the available ROV boat for bathymetry surveying in the market, an Indonesian product called SHUMOO is among the promising products - economically and practically proven using a few sample areas in Indonesia. The boat was equipped and integrated with systems of remote sensing technology, GNSS, echo sounder and navigational engine. It was designed for riverbed surveys on shallow area such as small /medium river, lakes, reservoirs, oxidation/detention pond and other water bodies. This paper tries to highlight the needs and enhancement offered to Malaysian' bathymetry surveyors/practitioners on the new ROV boat which make their task easier, faster, safer, economically effective and better riverbed modelling results. The discussion continues with a sample of Indonesia river (data collection and modelling) since it is mostly similar to Malaysia's river characteristics and suggests some improvement for Malaysia best practice.
\end{abstract}

\section{INTRODUCTION}

Bathymetry measurements and mapping technology is in greatly needed for several research areas such as in marine surveys. Information such as water depth, river alignment, obstacles along the riverbed served within bathymetry map which shared quite the same role as topographic maps in presenting the altitude and river features/accessories of the earth's surface at different geographic coordinates (Jawak et. al., 2015). An integration of both elevation such bathymetry and topographic, will produced seamless Digital Elevation Model (DEM) between riverbanks and riverbed for hydrographic river modeling (Karim et. el, 2017).

The use of maritime vessels to carry out multi-beam bathymetric survey is limited especially by depth of the waters. Small crafts such as fishing boats are suitable in shallow waters - especially connected water bodies. While, unconnected water bodies (such as oxidation pond and detention pond) are not suitable to conduct bathymetry survey using small fishing boats - mobilization limitation. But somehow, these unconnected water bodies are indeed need regular update in term of depth and maximum water volume to ensure the effectiveness of their operation in urban management.

The bathymetry or riverbed maps are use in many aspects such as monitoring of reservoirs, engineering, and planning (Hassan et. al., 2012; Romano et. al., 2012) concerning management and sustainability of water natural resources such as agriculture and agro-tuorism. For instance, Indonesia as an archipelago, selecting suitable bathymetry mapping method is very important since most of the country is covered by water (Setiawan et. al, 2014).

Through this paper, SHUMOO (Small Hydrography Marine Boundary Boat) will be introduced as a new technology for mapping bathymetry in shallow area as of the unmanned vehicle devices (ROV). SHUMOO capable in optimising bathymetry surveying method for shallow water area; capable to measure small-width river and in between riverbank and riverbed gaps which not covered by some other method. The innovation of this research product is the data and video are broadcast directly to the operator, enabling real time visualization and preprocessing phase.

The introduction section describes briefly on introductory of bathymetry maps, remote surveying device for shallow water and the need of this innovative approach. Section 2 explains literature background especially on current bathymetry practices in Malaysia. Section 3 describes the designed ROV bathymetry surveying boat while section 4 explains post-processing processes of the collected data toward riverbed modelling. Result and discussion of Indonesia case study will be presented in section 5. The last remaining section concludes the overall content of the paper with some suggestions.

\subsection{ROV bathymetry boat}

Since the dimensions was reduced from normal boat, the vessels are no longer manned and are categorized as Unmanned Surface Vehicles (USVs) (Caccia et. al., 2007; Bertram, 2016). By the analogy of avionics applications, they are also called marine 
drones (Giordano et. al., 2015). Some drones are also known as Autonomous Surface Crafts (ASCs) and Remotely Operated Vehicles (ROVs) as categorized by Zhao et. al. (2011). ASCs is also called autonomous surface vehicle (ASVs), are a kind of autonomous marine vehicle without the direct operation of humans, while ROVs are controlled by an operator who is not on-board. However, this distinction is not always observed according to analogy and the terms are sometimes used with no difference in meaning (Giordano et. al., 2016).

SHUMOO is a small boat integrated with systems of remote sensing technology, GPS and echo sounder - designed by group innovative students of Institut Teknologi Nasional, Malang, Indonesia. It capables of calculating depth of shallow water in between $0.5-100.0$ Meter depth. Boat navigation is connected with a modelling software, and measurement results are stored in (latitude, longitude \& depth) text format as the variables for bathymetric map (Suhari et. al., 2016). This boat has been proven and tested in a few study areas, especially in Indonesia. Some enhancements are properly made to increase the accuracy and quality of the boat to fit with Malaysia cases as the surveying communities and applications are concerned.

\subsection{The need of small rov boat}

Bathymetry maps in shallow area is difficult to obtain since present available tools only works for deep water such as in ocean and main river. Some difficulties in carry out bathymetry survey for small rivers, unconnected water bodies (refers to section 2) and processing/modelling limitations as discussed in Karim et. al. (2017) may directly affect accuracy of the model.

Field surveyors are indeed having challenges job or task in collecting accurate surface measurement, especially for unfamiliar areas as well as to measure riverbed surfaces. Safety precautions should always be the most priority aspect in carry out survey work especially for water body (unseen or unexpected dangers in water). There should be an alternative that surveyors should was given an option to carry out the job locally on the boat with the instrument or work remotely at the safe place (e.g. a survey station) by sending the UAV/ROV instrument to collect the data in dangerous/unknown territories.

\section{LITERATURE}

This section is divided into two main sub-sections; current field practice in riverbed elevation surveying and, available similar products in the market (ROV bathymetry surveying boat).

\subsection{Current practice in Malaysia}

There are two main data collection methods as typically practice among Malaysian surveyors; normal bathymetry (boat with surveyors on board) and using theodolite (total station or/and levelling instrument). Other approaches such as using Real Time Kinematic (RTK, see Figure 1), GPS with depth sounder devices (Latitude, Longitude and depth riverbed points, Figure 2) are also applicable for a certain application and surveyor's method.

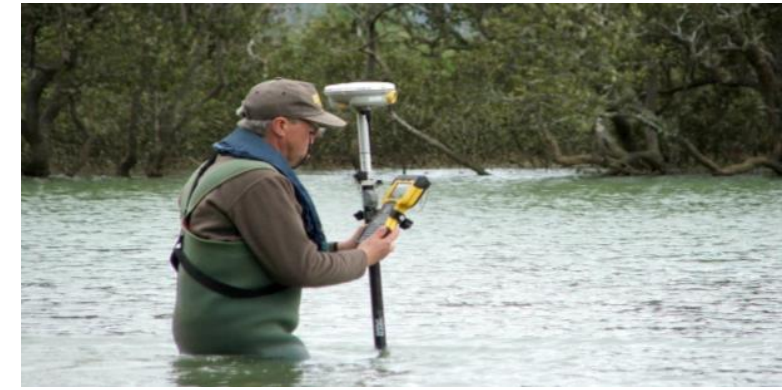

Figure. 1. Example of RTK cross-section survey (Underhill and Smellie, 2009).

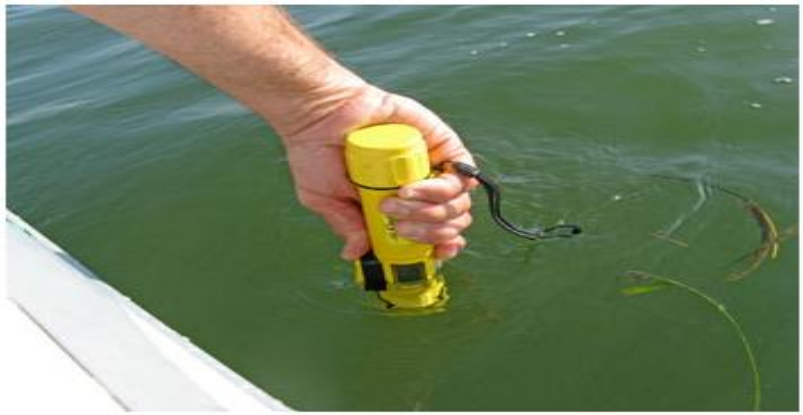

Figure. 2. Example of using depth sounder method (Irons, 2013).

\subsubsection{Bathymetry boat (surveyors on board)}

The main surveying method uses for measuring riverbed elevation in shallow water is a normal surveying technique bathymetry boat with surveyors and eco-sounder devices on board (Figure 3). This method usually best fit for the main river with more than 25 meter width in term of time and technique efficiency. However, medium size and small size rivers $(<10$ meters width) are not preferable because the size of the boat itself around $3-5$ meters long and quite difficult to acquire a straight cross section line.

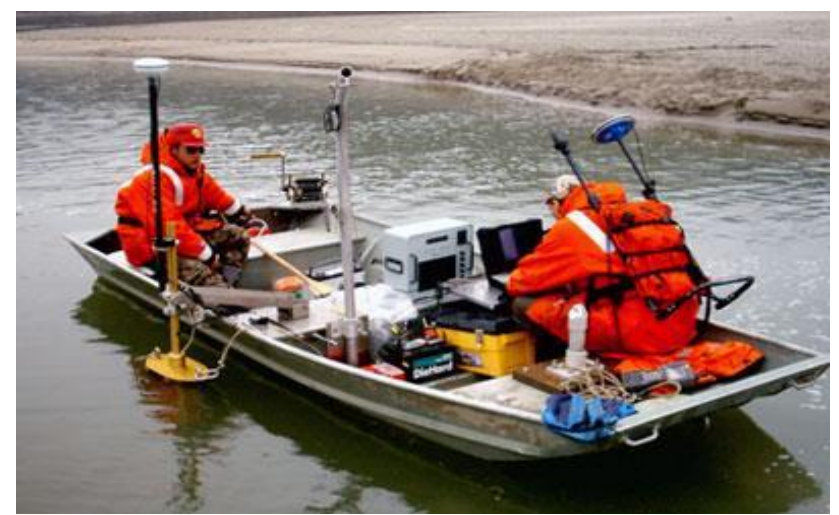

Figure. 3. Normal bathymetry surveying boat with surveyors on-board (USGS, 2006).

Some highlighted disadvantages as mentioned by Karim et. al. (2017) are difficulties in accessing sloping measurement in between riverbank and riverbed ( $2-4$ meters from riverbank) due to the size of the boat (U-turn distance/space) and obstacles (e.g. rocks, bushes etc.). Others than that, this method also would not guarantee the on-board surveyors safety (e.g. from hard currents, bad boat conditions and wild animals) as well as time consuming and expensive in cost. 
In some cases such as to measure the depth and volume of the water in separated water network such as a pond (oxidation pond, flood detention pond, lake), this technique will be at its disadvantages. Additional cost, time and man-power are required to mobilize the boat using road network to the targeted area / surveying site.

\subsubsection{Levelling instrument (levelling from riverbank stations)}

The second preferable method among riverbed/shallow water surveyors in Malaysia is using levelling instruments or theodolite (total station). This method uses transferred height from riverbank station (close to the chainage cross-section) to a series of points (depth) crossing the river using prism (e.g. in Figure 4). This technique suite for small river streams or river tributaries with water depth less than 1.5 meters (no actual river width preferred since it is directly depend on the distance accepted by theodolite to the measured point, normally around 300 meters). It is also a good method in measuring riverbed and volume of the separated water body such as lake and pond.

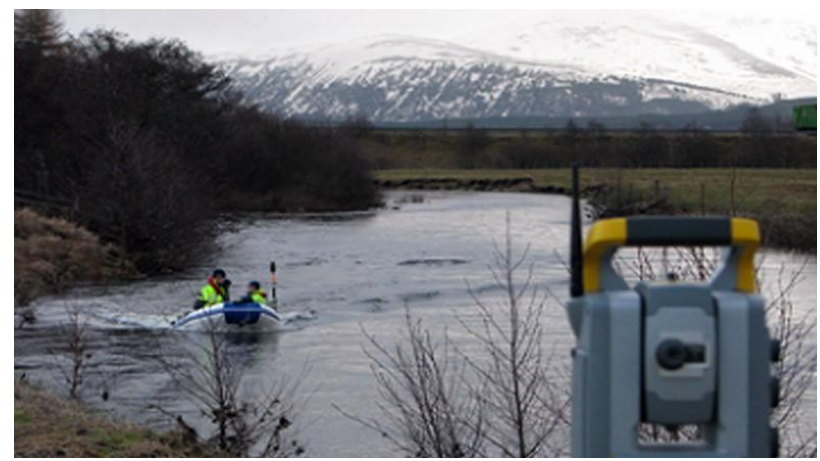

Figure 4. Example of a normal riverbed survey for small rivers (CainTech, 2014).

However, this method also has several limitations. Most of the theodolite or measuring instruments are not waterproofed and not suitable in raining and too hot (temperature) seasons. The sensitivity of the instruments to the extreme weathers affecting the accuracy and the condition of the instrument. The second limitation of this method is, additional devices and boat are needed to measure the water level which more than 2.0 meter depth: although is it is not recommended since it might affect the accuracy of the result.

\subsection{Related products in the market}

\subsubsection{Teledyne OceanScience Z-Boat 1800}

In USA, oceanscience launches Z-Boat 1800 ROV model for shallow water survey. The Teledyne OceanScience Z-Boat 1800 is a small ASV designed for underwater data collection with sonar system. Z-Boat is about 1.8 meters long with 0.9 meter wide vessel that weighs up to $68 \mathrm{~kg}$ in rugged configuration (Teledyne, 2012), see Figure 5. For positioning information, the Z-Boat uses a Trimble SPS-461 dual antenna GNSS receiver and the Airmar Smart Transducer for capturing water depth. This USV boat is quite heavy, space consuming as compared to SHUMOO (5 times heavier and 2 times bigger) and expensive as compared other products.

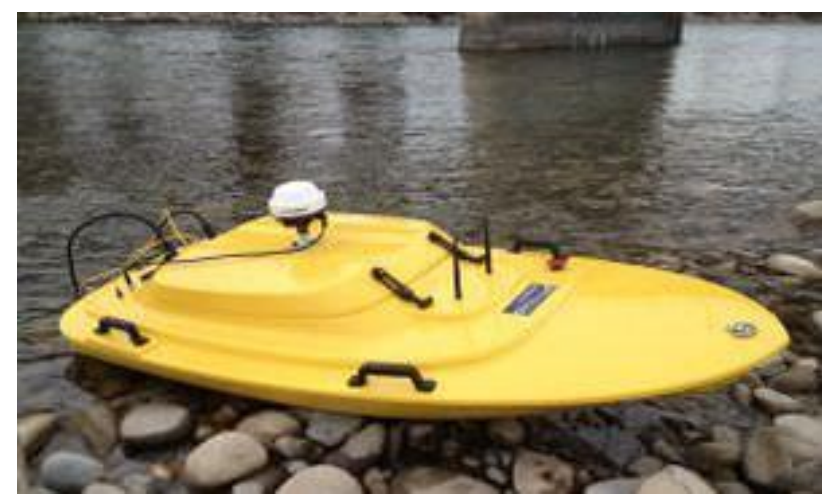

Figure 5 . Z-Boat 1800 (Teledyne, 2012)

\subsubsection{Geomar boat survey}

Geomar Survey Boat is a survey boat capable moving autonomously based on a set of predefined point seriess. Its dimension is approximately 1.2 meters long times 0.6 meter width, weights up to $22 \mathrm{~kg}$ with the fiberglass material shown in Figure 6. Geomar was designed with capability to survey over 1000 meter (3500 feet) horizontal range using radio signal with surface velocity up to 4 knots. Geomar offers turnkey surveygrade system with Seafloor Systems Echologger ECS 400, GNSS and reciever RTK positioning system allowing operator to view the boat track in real time on the shore ground station (Geomar, 2014). However, the boat was not designed based on research and the need from surveyor/client views. It is without the modeling integration and customized designs/components.

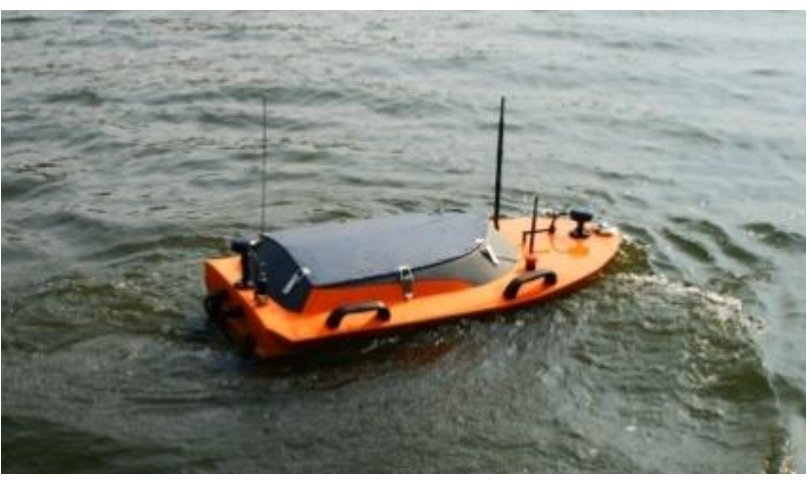

Figure 6. Geomar boat survey (Geomar, 2014).

\section{ROV HYDROGRAPHY BOAT}

A details process and ROV boat components, specifications and functionalities will be briefly explain in this section. Figure 7 show the general processes of the research and implementation.

\subsection{Tools and devices}

The designed ROV boat (physical specs as shown in Table 1) is a combination result of several major components:
a) Garmin GPSMAP585
b) Raspberry Pi 2
c) Remote Control
d) The interior and outer body design for the boat.
e) Modelling software
f) Navigation: Motor, propellers and servo 
Table 1. Characteristics of the ROV boat prototype.

\begin{tabular}{|l|c|c|}
\hline & Characteristics & Measure \\
\hline 1 & Overall Length & $130 \mathrm{~cm}$ \\
\hline 2 & Width & $35 \mathrm{~cm}$ \\
\hline 3 & Weight & $15 \mathrm{~kg}$ \\
\hline 4 & Motor & Brushless $750 \mathrm{kV}$ \\
\hline 5 & Power & $4 \mathrm{~h}$ \\
\hline 6 & Body material & Fiberglass \\
\hline 7 & Echologger & Differ $/ \mathrm{spec}$ \\
\hline 8 & GNSS Receiver & Differ $/ \mathrm{spec}$ \\
\hline
\end{tabular}

\subsection{Overall operation workflows}

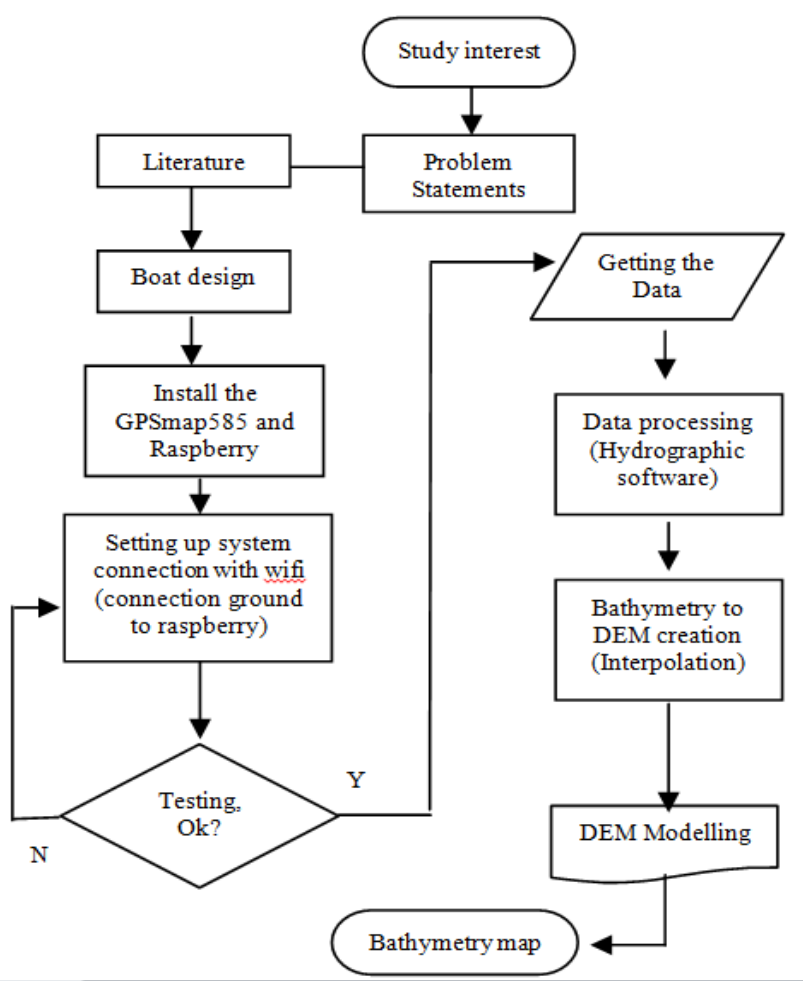

Figure 7. General workflow process for system setup (e.g. using GPSmap585) and processing.

\subsection{System design}

The ROV was designed to integrate with Solidwork software (for real time modelling at the surveying site). The body of the boat was made out from a few layer of fiberglass material. While for the navigation, it was equipped with propellers, motors, and servo - control remotely using remote control device. It equipped with two control modes, a tele-operated mode and way point mode. A tele-operated mode is achieved through a $2.4 \mathrm{GHz}$ ACE $\mathrm{RC}$ radio transmitter which range about $700 \mathrm{~m}$. Besides, in way point mode, Andromax m25 Modem $512 \mathrm{Mhz}$ is used to provide point to point communication with base station from riverbank/station. However, it can be modified on request to install radio signal for logger distance travel.

\subsection{Communication and transmitting data}

The boat is controlled by remote control within the range +500 meters. This measurement score was determined by the connectivity of the wireless of radio signal. Previous prototype was using wifi waves system with range +300 meter. Longer distance than its reach may cause the software reads the boat position and depth measurement with inconsistent strength (loss of signal, no returned data). Figure 8 and 9 show the wifi communication between on board boat with the laptop (downloading data).

The communication flow and process is illustrated in Figure 5 and Figure 6. There are three main connection phases on board connectivity after receiving singnal from remote control and before upload the data to the receiver (laptop).

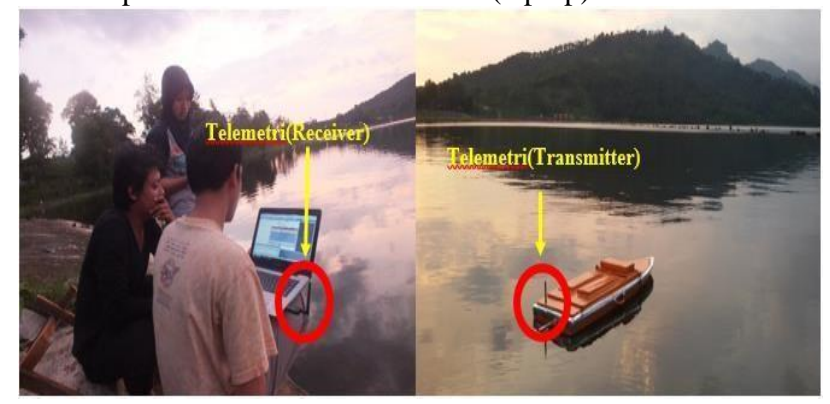

Figure 8. Receivers for ROV boat and laptop (data download)

The navigation maneuverer of SHUMOO is controlled by a remote control on the ground. Depth and position data will be broadcasted via wireless in real-time and received by computer on the ground. Besides, navigation log (Latitude, Longitude) and depth (Z, relatively upon water surface level - before correction) data will be visualized using a customized modelling software.

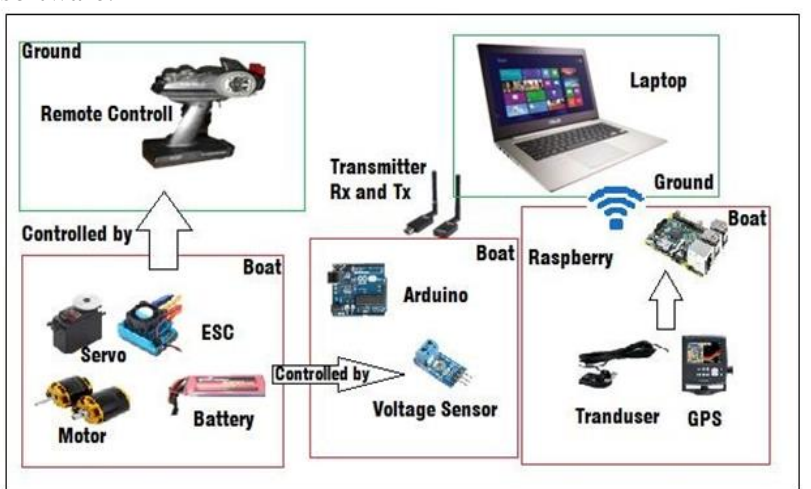

Figure 9. Example of major components and the communication architecture (Suhari, 2016).

\subsection{Navigation and power supply}

Nnavigation and positioning system of the boat uses Garmin GPS585 fish finder with accuracy 5-7 meter. Two sensors were used; RS232 (pressure and humidity transmitter) and NMEA 0183 (GPS sensor with screen) which are compatible and easy for integration purposes. Raspberry uses transmit NMEA data to the laptop and vehicle and maneuverer controlled by remote control device. The boat navigation (navigation $\log$ ) can be monitored using modelling software.

The boat's power supply system consists of two $12 \mathrm{~V} / 5200 \mathrm{mAH}$ batteries connected in series format, which provide a consistent $24 \mathrm{~V}$ nominal voltage for the brushless motor for four hours. Sensitive devices such as sensors and computer system use independent energy supply with Li-ion $12 \mathrm{~V} 9800 \mathrm{mAH}$ battery pack. Additional DC/DC converter is used to provide power sharing between the devices. 


\section{DATA PROCESSING (INDONESIA CASE STUDY)}

A case study on bathymetry surveying using the SHUMOO boat was conducted for a 1.5 kilometres of Anyar Buring River, Malang, Indonesia. The river was about 10 meters width (Figure 10) which is not suitable to use normal bathymetry method (boat with surveyors on board, as discussed in section 2.1).

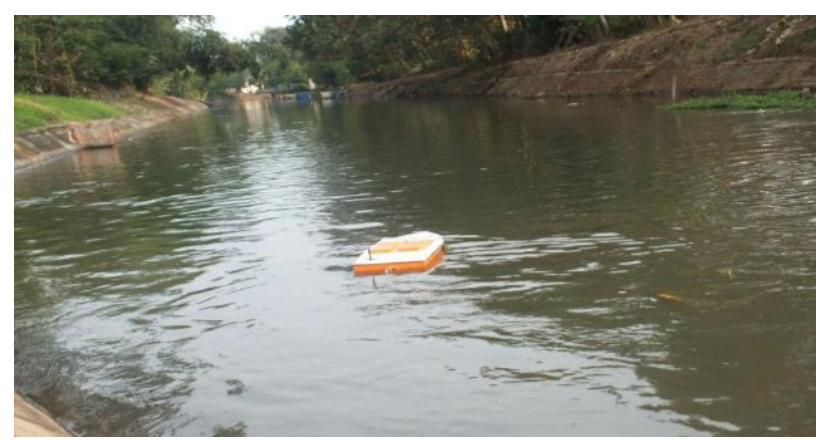

Figure 10. The study area, Anyar River.

\subsection{Surveying method}

The surveying method and procedure involve several stages as follow (Suhari and Gunawan, 2017):

1) Obtain and download image of observation site form the internet.

2) Design sounding survey from navigation software

3) Start the survey and collect the data coordinate from GPS satelite and depth from transducer GPSMAP585.

4) Analysis, interpolation, and processing the data

5) Map the collected data for visualization purposes.

6) Export the data and overlay from other software.

Latitude and longitude of the boat is determined by GNSS satelite receiver and will be stored in GPSMAP585 (Figure $11-$ overall process). GPSMAP585 transfers the sonar from transducer and received the depth $(\mathrm{z})$ data. Position and depth (Latitude, Longitude ,-z ; z from water surface to riverbed) will be transferred to the receiving or modelling device (laptop or personal computer). Minimum two surveyors are needed to maintain the navigation of the boat while monitoring the laptop and manuver by remote control on the ground. After the site surveying, latitude, longitude and depth data will be processed and the analysis such as interpolation and creating the map or simulation will be done in the office.

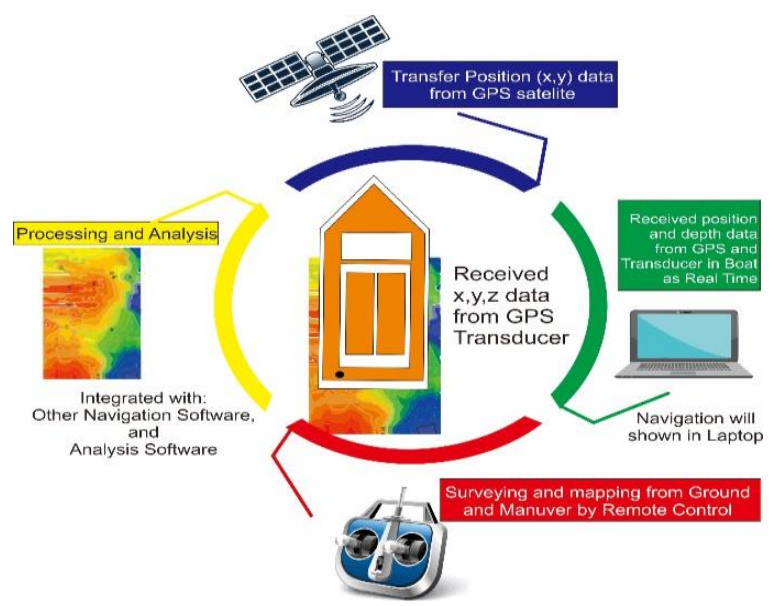

Figure 11. Surveying procedure using ROV boat.

\subsection{Data processing}

A series of raw data with temporal log was recorded in NMEA GPS sensor as shown in Figure 12. This data can be view graphically using laptop monitor for a real time location (Latitude, Longitude).

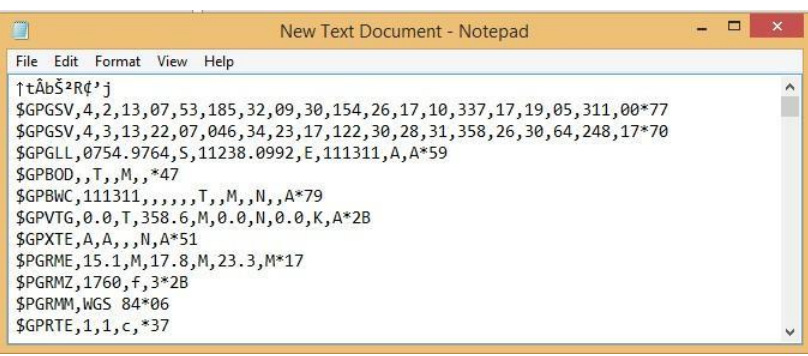

Figure 12. NMEA metadata and real encoded data.

NMEA data will then be combined with the echolloger temporal data (depth - distance between water surface/boat with the riverbed). After a semi - automatic correction between these two downloaded data from the the boat, a series of XYZ coordinate of river cross-section will be acquired in World Traverse Macator (WGS 1984) projection system. The coordinate was then be projected to a local coordinate system, projection 49 UTM Zone (local coordinate for Malang District, Indonesia). An example of final bathymetry points data are shown in Figure 14.

\subsection{Riverbed modelling}

Karim et. al. (2017) describes a new technique on blending (fusion) both riverbed and topographic elevation into a single Digital Elevation Model (DEM). However, in this study, we only obtained the riverbed elevation and a merging technique of two different interpolation methods can be done to increase the riverbed surface accuracy and enhance visualization. Thus, this paper tries to describe the results of normal interpolation and suggested merging technique in riverbed modelling (section $5.1 .2)$.

\section{RESULTS AND DISCUSSION}

This section will briefly describe surveying results (raw as well as modelling techniques) and potential implementation for Malaysia case study. Accuracy improvement of surveyed data and modelling results of Anyar River will be discussed and suggested at the end of this section.

\subsection{Surveying results}

Bathymetry survey result normally comes out in a series of latitude, longitud and depth or coordinates with depth or riverbed elevation (after correction). After the correction, an interpolation technique normally take place for a continues riverbed modelling.

\subsubsection{Collected latitude, longitude and depth data}

The collected data was in negative (-) signed which indicate that the measurement or distance measured below river water surface (riverbed, illustrated in Figure 13). Two elevation correction need to be carried out: add the hight of the boat (distance in between echolloger's sensor to water surface of the 
river) and transfering the height of the base stations (normally use static GNSS receiver - RTK) of corresponding crosssections. After correction or adjustment of the collected data, a positive signed elevation will be acquired (higher than the mean sea level - MSL for upper stream river) as shown in Figure 14. Figure 15 shows the collected bathymetry points at study area.

\begin{tabular}{|c|c|c|c|c|}
\hline \multicolumn{2}{|c|}{ 目 SungaiAnyar.bat $x$} & \multicolumn{2}{|c|}{ 罗 Hasil-negative-depth-original.txt $\mathbf{\square}$} & \multirow{3}{*}{$\begin{array}{l}-0.88 \\
-0.88\end{array}$} \\
\hline 1163 & 1163 & 681302.414 & 9114719.954 & \\
\hline 1164 & 1164 & 681302.414 & 9114719.954 & \\
\hline 1165 & 1165 & 681302.414 & 9114719.954 & \\
\hline 1166 & 1166 & 681301.863 & 9114719.956 & .91 \\
\hline 1167 & 1167 & 681301.863 & 9114719.956 & \\
\hline 1168 & 1168 & 681301.496 & 9114720.142 & -0.79 \\
\hline 1169 & 1169 & 681301.496 & 9114720.142 & -0.79 \\
\hline $\begin{array}{l}1170 \\
1171\end{array}$ & 1170 & $681301 \cdot 496$ & 9114720.142 & -0.69 \\
\hline $\begin{array}{l}1171 \\
1172\end{array}$ & $\begin{array}{l}1171 \\
1172\end{array}$ & 681300.763 & 9114720.514 & -0.69 \\
\hline $\begin{array}{l}1172 \\
1173\end{array}$ & $\begin{array}{l}1172 \\
1173\end{array}$ & $\begin{array}{l}681300.763 \\
681300.584\end{array}$ & $\begin{array}{l}9114720.514 \\
9114721.805\end{array}$ & $\begin{array}{l}-0.69 \\
-0.67\end{array}$ \\
\hline 1174 & 1174 & 681300.584 & 9114721.805 & -0.67 \\
\hline 1175 & 1175 & 681300.589 & 9114722.911 & -0.78 \\
\hline 1176 & 1176 & 681300.589 & 9114722.911 & -0.86 \\
\hline 1177 & 1177 & 681300.041 & 9114723.835 & -0.86 \\
\hline 1178 & 1178 & 681300.041 & 9114723.835 & 86 \\
\hline 1179 & 1179 & 681299.493 & 9114724.574 & 83 \\
\hline 1180 & 1180 & 681299.493 & 9114724.574 & 83 \\
\hline 1181 & 1181 & 681299.494 & 9114724.943 & \\
\hline 1182 & 1182 & 681299.494 & 9114724.943 & .88 \\
\hline 1183 & 1183 & 681299.68 & 9114725.311 & 87 \\
\hline 1184 & 1184 & 681300.969 & 9114726.043 & -0.87 \\
\hline $\begin{array}{l}1185 \\
1186\end{array}$ & $\begin{array}{l}1185 \\
1186\end{array}$ & $681301 \cdot 155$ & 9114726.779 & -0.89 \\
\hline & & & & \\
\hline
\end{tabular}

Figure 13. Before correction (-ve signed elevation - depth).

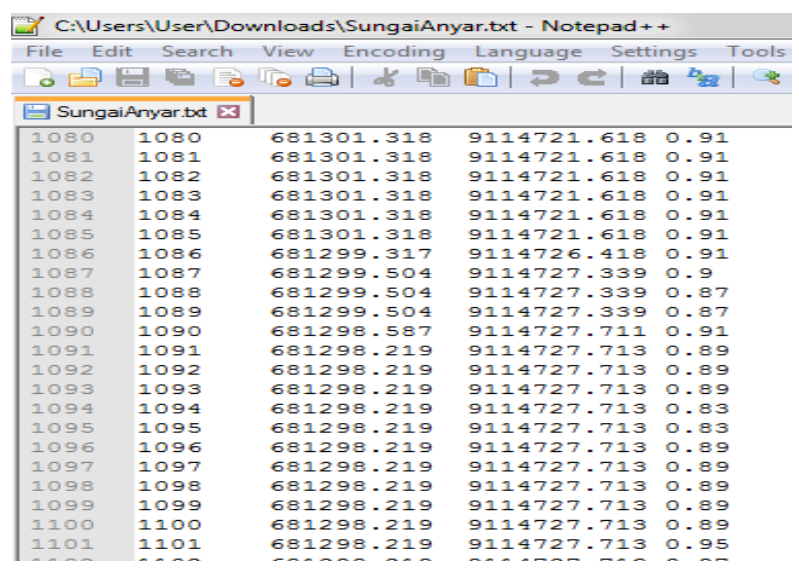

Figure 14. After correction (+ve signed of riverbed elevation).

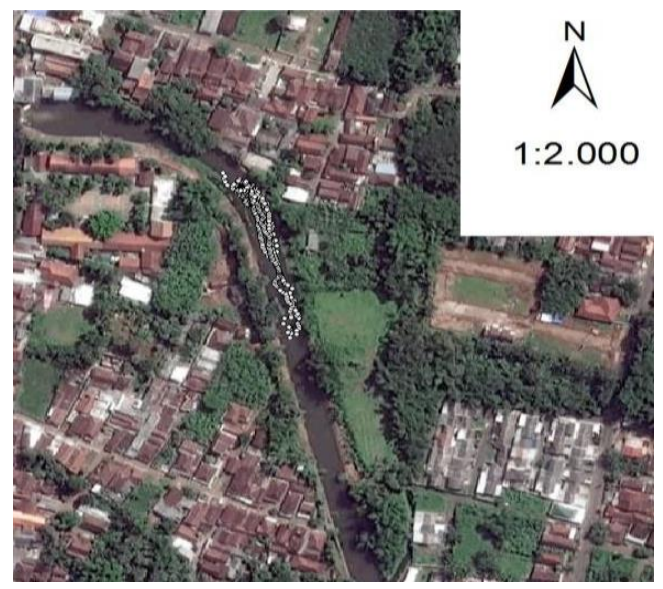

Figure 15 . Corrected bathymetry points elevation.

\subsubsection{Interpolation for riverbed modelling}

Figure 16 shows a normal interpolation result obtained using Kringing interpolation technique and is overlay with the satellite base image. 3D interpolated riverbed modelling with Google Imagery is illustrated in Figure 17. However the result can be enhanced if we do the merging with ratio between two different interpolation techniques (Karim et. al., 2017) such as illustrated in Figure 18.
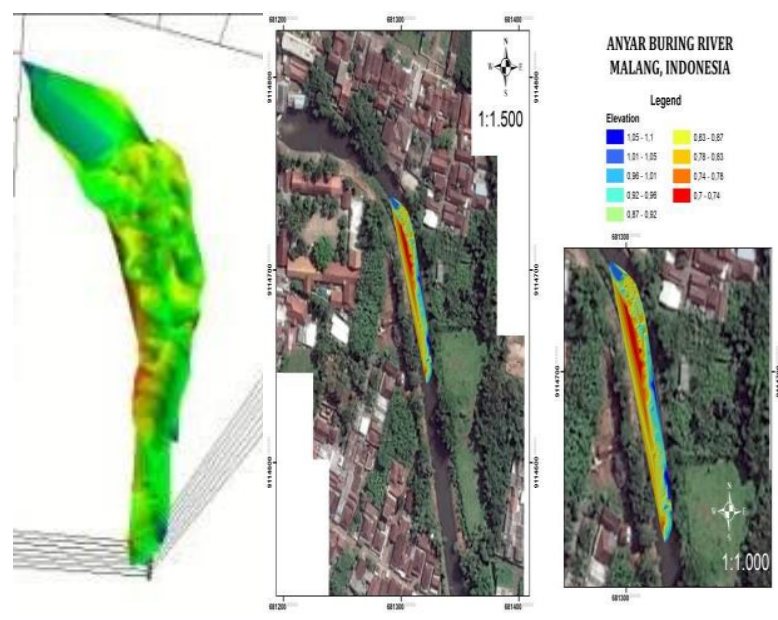

Figure 16. Example of normal bathymetry map/interpolation for continues riverbed model.

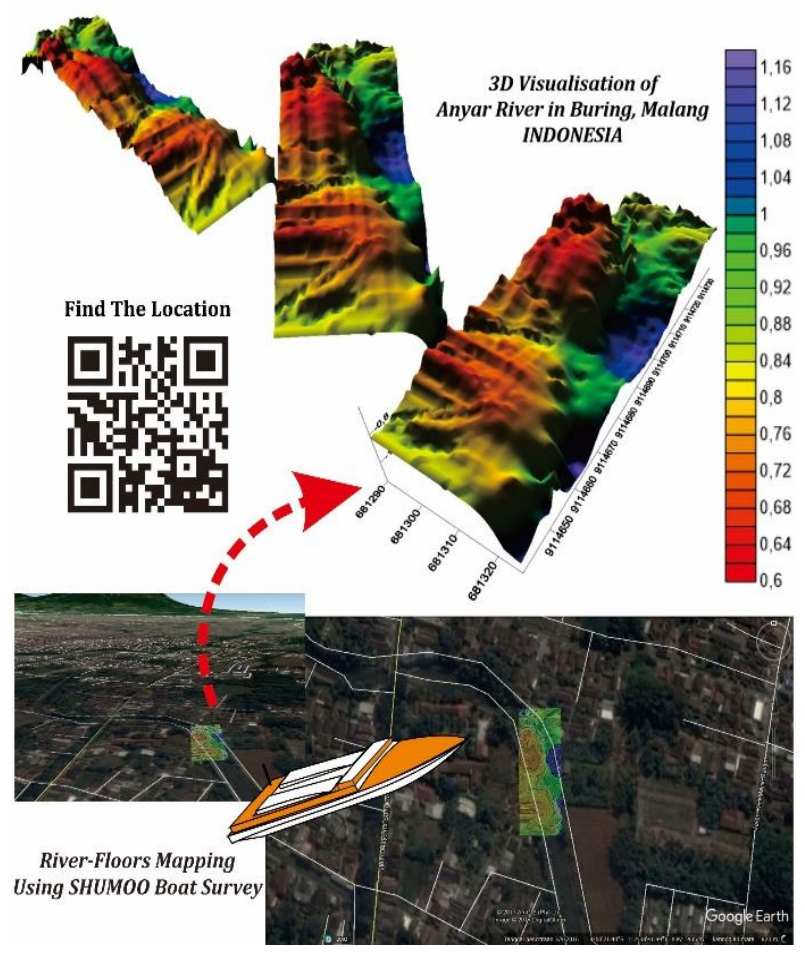

Figure 17. 3D visualization of Anyar River-floor (Suhari, 2017). 


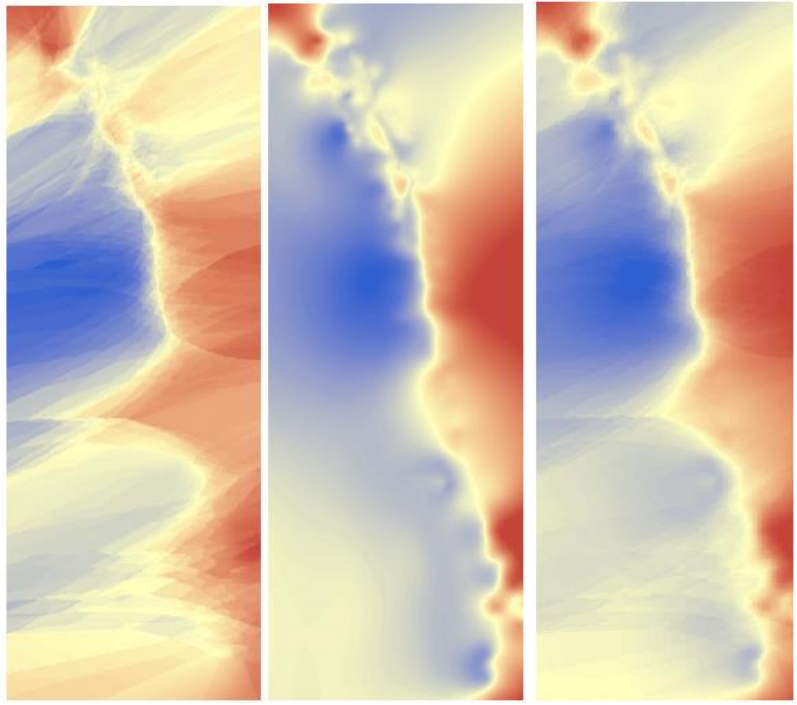

Figure 18. From left: Kriging, Topoggraphic and merging both interpolation techniques with ratio $50 \%$ each.

\subsection{Potential implementation for Malaysia}

Karim et. al, (2017) describes that one of the major drawback on current bathymetry practice in Malaysia is on the accessibility of measure sloping riverbank. The boats hardly measure the slope (2-3 Meter from riverbank to the riverbed) because the size of surveying boat $(15-21$ Feet long, difficult to make a U-turn) and obstacle such as bush or rock. Current practices (methods) also are not suitable for all study area (cases) such as pond and small or medium-size rivers for the $1^{\text {st }}$ method; depth more than 2.0 Meters and not suitable for extreme weather conditions for the $2^{\text {nd }}$ method as discussed in Section 2.

Some improvements on the existing prototype will also influence the surveyors' interest in Malaysia. For example, stable boats design that capable to endure the current of the local rivers (speed of the water flowing to downstream). Several highlighted improvements include:

1.New design for exterior and interior of the boat (Figure 19)

2.Accuracy improvement (Latitude, Longitude) - better GNSS receiver

3.The use of radio signal for communication and downloading data - longer survey distance from the station.

4.Integration of open source modelling software.

5.Autonomous mode

\section{Specification of physical}

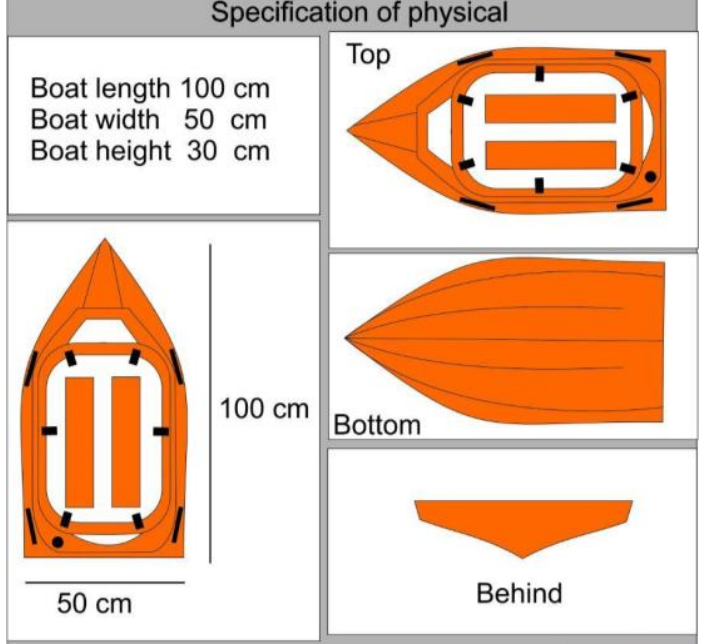

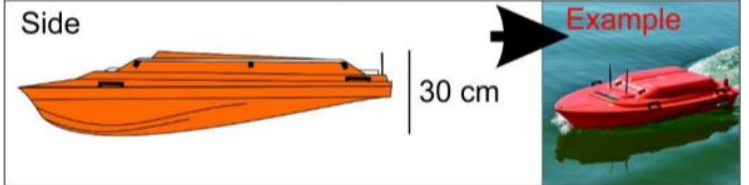

Figure 19. New design for water resistance/endurance.

\section{CONCLUSION}

This paper describes the innovation of a small boat integrated with a system of remote sensing technology, GNSS receiver, echo sounder and modelling software. Possibility to be use in Malaysia as future practise instrument also being discussed especially on current bathymetry problems, potential of implementation and suggestion for better performances. A sample of Anyar River bathymetry survey results was described as the pilot testing for the $1^{\text {st }}$ prototype generation.

Since there are still less similar products in Asian region and this boat considers among the cheapest available in the market, the authors believe that this research/innovative product suites to the need of bathymetry surveyors; can be commercialize near the future. However, some enhancements are necessary to upgrade the components from prototype to the commercial level either in accuracy, design and functionalities.

As for the next research direction, we plan to access the upgraded version of the ROV boat in term of accuracy; comparative study with the available bathymetry methods in Malaysia and pilot study on Malaysia rivers.

\section{REFERENCES}

Bertram, V., 2008. Unmanned Surface Vehicles-A Survey. [Online]: http://www.skibstekniskselskab.dk/public/dokumenter/Skibsteknisk/Do wnload\%20materiale/2008/10\%20marts\%2008/USVsurvey_DTU.pdf (accessed on 01 June 2017).

Boehm B., Hansen W. J., 2000. Spiral Development: Experience, Principles, and Refinements; (No.CMU/SEI-2000-SR-008); Software Engineering Institute: Pittsburgh,PA,USA,2000; pp.1-35.

Caccia M., Bibuli M., Bono R., Bruzzone G., Bruzzone G., Spirandelli E., 2007. Unmanned surface vehicle for coastal and protected waters applications: The Charlie Project. Mar. Technol. Soc. J. 2007, 41, 6271 .

CainTech, 2014. River Spey Cross-Section Survey, Kingussie.

Scotland. [Online project report].

http://www.caintechltd.com/project/river-spey-cross-section-survey-

kingussie/ . Accessed on July 2017.

Giordano F., Mattei G., Parente C., Peluso F., Santamaria R., 2016. Intergrating Sensors into a Marine Drone for Bathymetric 3D Surveys in Shallow Waters. Sensors 2016, 16, 41; doi: 10.3390/ s16010041

Giordano F., Mattei G., Parente C., Peluso F., Santamaria R., 2015. MicroVeGA (micro vessel for geodetics application): A marine drone for the acquisition of bathymetric data for GIS applications. ISPRS Int. Arch. Photogramm. Remote Sens. Spat. Inf. Sci. 2015, 1, 123-130.

Hassan S.R., Zakaria M., Arshad M.R., Aziz Z.A., 2012. Evaluation of Propulsion System used in URRG-Autonomous Surface Vessel (ASV). Proceeding Eng. 2012, 41, 607-613.

Irons J., 2013. Using a Handheld Depthsounder. [Online Magazine] http://www.sailmagazine.com/cruising/cruising-tips/using-a-handhelddepthsounder/ Access on June 2017. 
Jawak S.D., Vadlamani S.S., Luis A.J., 2015. Models, Methods and Comparisons. Adv. Remote Sens: A Synoptic Review on Deriving Bathymetry Information using Remote Sensing Technologies. 2015, 4 , $147-162$.

Karim, H., M.G. Hashim, and M. Salleh M.R., 2017. A Blending Technique for Topograhic and Hydrographic DEMs. Geomatics and Geospatial Technology (GGT) 2017. 03-04 October 2017. Kuala Lumpur. ISPRS Archieved. [IN PROGRESS].

Romano A., Duranti, P., 2012. Autonomous Unmanned Surface Vessels for Hydrographic Measurement and Environmental Monitoring. In Proceedings of the FIG Working Week 2012, Knowing to Manage the Territory, Protect the Environment, Evaluate the Cultural Heritage, Rome, Italy, 6-10 May 2012; pp. 1-15.

Setiawan H., Rachman M.D., Yara G.D., Aprillisianti A., Amanda S., 2014. Teknologi Wireless Automatic Nahkoda for Ship. Program Kreativitas Mahasiswa - Karsa Cipta.

Suhari K.T, Apryandika K.S, Rahmawati, Hasan M.Z, and Purwanto H. 2016. "The Small Hydrography Marine Boundary Boat (SHUMOO for Mapping Bathymetry of Shallow Water Areas". in Proceedings of The 1st Geomatics International Conference (GEOICON) 2016 "Utilization of Satellite Technology for Natural Resources Exploration". ITS Surabaya, Indonesia.

Suhari K.T., and Gunawan P.H. 2017. The Anyar River Depth Mapping from Surveying Boat (SHUMOO) Using ArcGIS and Surfer. In $3^{\text {rd }}$ International Conference on Control, Electronics, Renewable Energy, and Communications 2017 (ICCEREC 2017). 26-28 September 2017. Yogyakarta - Indonesia. [IN PROGRESS]

Underhill J., and Smellie P., 2009. [Online articles]. Regional Council Wades into River Survey.

http://business.scoop.co.nz/2009/11/04/regional-council-wades-intoriver-survey/ . Acessed on July 2017

USGS, 2006. Hydrographic Surveys: Overview and Method. [Online portal]. https://water.usgs.gov/osw/gps/GPS_projects.html. Accessed on July 2017.

Zhao J., Yan W., Jin X., 2011. Brief Review of Autonomous Surface Crafts. ICIC Expr. Lett. 2011, 5, 4381-4386. 